\title{
Youthcenter Di Kebumen Sebagai Wadah Pengembangan Kreativitas Remaja Dengan Pendekatan Psikologi ARSITEKTUR
}

\author{
Fahlevi Ismail, Amin Sumadyo, Fauzan Ali Ikhsan \\ Program Studi Arsitektur \\ Jurusan Arsitektur Fakultas Teknik \\ Universitas Sebelas Maret Surakarta \\ Email : fhlvsml@gmail.com
}

\begin{abstract}
There are many communities, teen clubs and events held in the city of Kebumen, this is a sign that the local youth have the potential to show the creativity and existence. This phenomenon needs to be balanced with the provision of a wide range of facilities to accommodate youth activities such as sports facilities, arts facilities and community facilities. The facility in the city of Kebumen still minimal and insufficient for the scale of the city. Design Youth Center in Kebumen City aims to get the design of the building to facilitate sports activities, arts and community activities into the shape of the building is able to accommodate youth to enhance the creativity of teenagers. Design issues are: how the expression of space and form of the building that can accommodate the adolescent approach to Architectural Psychology is then translated into the design of the container Youth Center in Kebumen. The method used is a method of designing the architecture, from the collection of data was then analyzed by functional programming, programming performance and architectural analysis. Concept design: Architectural Psychology applied to the expression of space and forms building Youth Center is expected to bring the design of the building is able to accommodate adolescent psychology to be more creative in the activities in it.
\end{abstract}

Keywords: Adolescent, Architecture Psychology (psychophysical aspects), Creativity, Kebumen, Youth Center.

\section{PENDAHULUAN}

Pemuda adalah aset masa depan bangsa. Dalam rangka membangun kepemudaan, maka Kabupaten Kebumen di masa mendatang mempunyai harapan besar untuk dikelelola oleh generasi yang fair-play. Kondisi pemuda dalam bidang olahraga dan kebudayaan Kabupaten Kebumen sekarang ini cukup memprihatinkan. Menurut DIKPORA, yang menyebabkan kondisi kepemudaan menurun, di antaranya adalah minimnya sarana dan prasarana olahraga dan kesenian, belum adanya gedung olahraga dan kesenian yang memadai, terbatasnya tenaga pembina olahraga dan kesenian yang professional, banyaknya kelompok kesenian yang belum mendapat pembinaan memadai dan minimnya prestasi olahraga dan seni, berdasarkan informasi yang didapat melalui website www.dikpora.kebumenkab.go (7 september 2014).
Sementara itu banyak sekali komunitas, klub dan event remaja yang diadakan di Kota Kebumen, hal ini merupakan tanda bahwa remaja setempat mempunyai potensi untuk menunjukan kreativitas dan eksistensinya. Dalam bidang olahraga terdapat beberapa cabang yang setiap tahunnya terlaksana event tersebut seperti sepak bola, futsal, bulu tangkis, catur dan juga basket. Event olahraga ini perlu wadah untuk kegiatan di hari-hari biasa agar remaja tidak lari ke hal yang negatip. Kegiatan pertunjukan seni sering di gelar di Kebumen. Forum Pekerja Seni Teater Kebumen (FOPSET) sering menyelenggarakan ajang ini untuk mencari bakat-bakat remaja kebumen. Selain itu komunitas untuk kesenian tradisional di Kebumen juga tidak kalah banyak diantaranya ada Kuda Lumping, Wayang Kulit, Kethoprak, Lengger, Jam Janeng dan Sanggar Seni (BPS Kebumen, 2014). Event remaja lainya adalah Kebumen Youth Fest, yang kegiatanya adalah: Band 
Perfomance, BMX, Skateboard Perfomance, Distro Ekspo, Fashion Show, Campus Expo, dll yang penyelenggaraanya seadanya dan minim fasilitas karena belum adanya ruang remaja di kota ini. Keberadaan Youth Center mutlak dibutuhkan untuk mewadahi berbagai macam kegiatan tersebut.

Youth Center ini direncanakan untuk dapat memenuhi tuntutan kebutuhan ruang remaja agar dapat mewadahi kegiatan mereka. Remaja yang identik dengan jiwa yang ekpresif, dinamis dan juga aktif merupakan hal yang harus diperhatikan dalam mendesain sebuah wadah untuk mereka. Aspek keamanan psikologi dan juga kebebasan psikologis menjadi syarat penting untuk terciptanya kondisi lingkungan yang dapat mengembangkan kreativitas. Psikologi Arsitektur adalah pendekatan arsitektur yang penerapanya selalu menyertakan pertimbangan- pertimbangan perilaku penguna dalam proses perancangan (Halim, 2005). Kaidah-kaidah dalam disiplin ilmu Psikologi Arsitektur diharapkan mampu untuk menciptakan atau merekayasa sebuah wadah yang sesui dengan dinamika remaja dan juga membuat sebuah kondisi lingkungan yang dapat menstimulan kreativitas remaja.

\section{METODE}

Metode yang digunakan dalam memperoleh rancangan Youth Center di Kebumen didasarkan pada penerapan prinsipprinsip Psikologi Arsitektur sebagai berikut.

\subsection{Macam dan Teknik Pengumpulan Data}

1. Data Potensi Remaja Kebumen: didapat melalui survey lapangan, wawancara dan juga melalui situs-situs komunitas mereka dan situs berita online seperti www.kebumenkab.go.id, dan www.beritakebumen.info,

2. Data Fasilitas Remaja: didapat melalui data instansional Pemkot, melalui survey lapangan serta melalui situs dan artikel terkait.

3. Studi Literatur merupakan tahapan mencari informasi melalui buku-buku referensi, situs-situs internet. Studi literatur tersebut terdiri dari
a. Psikologi Remaja
b. Proses Kreativitas
c. Psikologi Arsitektur
d. Psikologi warna dan bentuk

4. Sistem Struktur: data didapat dari mata kuliah tentang struktur serta beberapa buku referensi.

\subsection{Metode Analisis Data}

Analisis perencanaan (building concept) mengidentifikasi masalah yang ada berdasarkan konsep rancangan Youth Center yang diselesaikan dengan pendekatan Psikologi Arsitektur sebagai metode arsitektural. Psikologi Arsitektur mampu menjadi sebuah bidang kajian lintas disiplin yang dapat digambarkan sebagai sekeping mata uang logam yang memiliki dua sisi; sisi arsitekturalnya menggambarkan aspek fisik buatan manusia dan sisi psikologisnya menggambarkan aspek mental manusia (Halim, 2005).

Analisis perancangan (building criteria) dilakukan dengan mengolah data yang telah terkumpul dan dikelompokkan berdasarkan pemrograman fungsional, performansi, dan arsitektural.

1. Pemograman fungsional bertujuan untuk mengidentikasi pengguna Youth Center, di antaranya pelaku kegiatan, jenis kegiatan, pola kegiatan, sifat kegiatan, sifat organisasi.

2. Pemograman performansi menerjemahkan secara sistematik kebutuhan para pengguna Youth Center beserta fasilitasnya ke dalam persyaratan pemilihan tapak, persyaratan kebutuhan ruang, persyaratan besaran ruang dan program ruang, serta penggunaan selubung bangunan.

3. Analisis arsitektural merupakan tahap penggabungan dari hasil identifikasi kedua analisa sebelumnya (fungsional dan performansi). Dalam proses ini akan menganalisa masalah massa, ruang, tampilan, pengolahan tapak, utilititas, dan struktur bangunan.

\section{ANALISIS}

\subsection{Analisis Faktor Manusia}

Tabel 1. Pelaku Kegiatan

\begin{tabular}{|l|l|l|}
\hline $\begin{array}{l}\text { Pelaku } \\
\text { Kegiatan }\end{array}$ & Kegiatan & $\begin{array}{l}\text { Kebutuhan } \\
\text { Ruang }\end{array}$ \\
\hline \multirow{3}{*}{ Pengunjung } & \multirow{2}{*}{$\begin{array}{l}\text { Bidang } \\
\text { Olahraga }\end{array}$} & Lapangan voli \\
\cline { 3 - 3 } & & Jogging Track \\
\cline { 3 - 3 } & & Lapangan futsal \\
\hline
\end{tabular}




\begin{tabular}{|c|c|c|}
\hline & & $\begin{array}{l}\text { Lapangan } \\
\text { Badminton }\end{array}$ \\
\hline & & $\begin{array}{l}\text { Lapangan tenis } \\
\text { meja }\end{array}$ \\
\hline & & Lapangan basket \\
\hline & & Arena catur \\
\hline & \multirow{5}{*}{$\begin{array}{l}\text { Bidang } \\
\text { Kesenian }\end{array}$} & Arena melukis \\
\hline & & Studio handicraft \\
\hline & & Studio musik \\
\hline & & Studio drama \\
\hline & & Studio tari \\
\hline & \multirow{5}{*}{ Bidang Hobbi } & Studio fotografi \\
\hline & & Arena skateboard \\
\hline \multirow{9}{*}{ Pengunjung } & & arena $B M X$ \\
\hline & & $\begin{array}{l}\text { Arena wall } \\
\text { climbing }\end{array}$ \\
\hline & & Studio film \\
\hline & \multirow{3}{*}{$\begin{array}{l}\text { Bidang } \\
\text { Komunitas }\end{array}$} & $\begin{array}{l}\text { Ruang komunitas } \\
\text { kesenian } \\
\text { tradisional }\end{array}$ \\
\hline & & $\begin{array}{l}\text { Ruang } \\
\text { Komunitas } \\
\text { FOPSET }\end{array}$ \\
\hline & & $\begin{array}{l}\text { Ruang komunitas } \\
\text { lokal }\end{array}$ \\
\hline & \multirow{3}{*}{$\begin{array}{l}\text { Kegiatan } \\
\text { penunjang }\end{array}$} & Ruang Seminar \\
\hline & & Perpustakaan \\
\hline & & Playground \\
\hline \multirow{3}{*}{$\begin{array}{l}\text { Pengelola dan } \\
\text { Karyawan }\end{array}$} & \multirow{3}{*}{$\begin{array}{l}\text { Pengelolaan dan } \\
\text { pengawaan }\end{array}$} & Ruang Kerja \\
\hline & & Ruang Rapat \\
\hline & & Servis \\
\hline
\end{tabular}

Pada Tabel 1 terlihat pelaku kegiatan, Kegiatan dan kebutuhan ruang apa saja yang diperlukan untuk Kebumen Youth Center

Peruangan dalam Youth Center ini kemudian dikelompokan menjadi lima zona peruangan untuk memudahkan dalam proses mendesain yaitu meliputi: kelompok zona kegiatan penerima, kelompok zona kegiatan utama, kelompok zona kegiatan penunjang, kelompok zona kegiatan pengelola, dan kelompok zona kegiatan servis.

Selanjutnya dibuat pola hubungan dan organisasi ruang sebagai berikut :

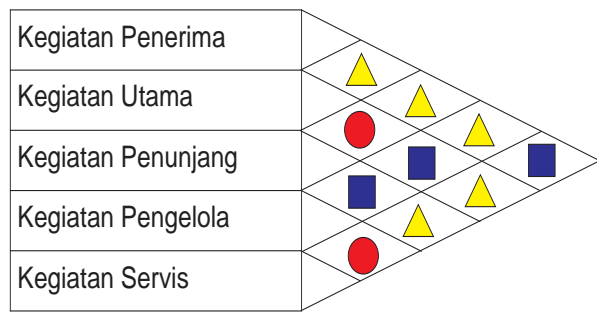

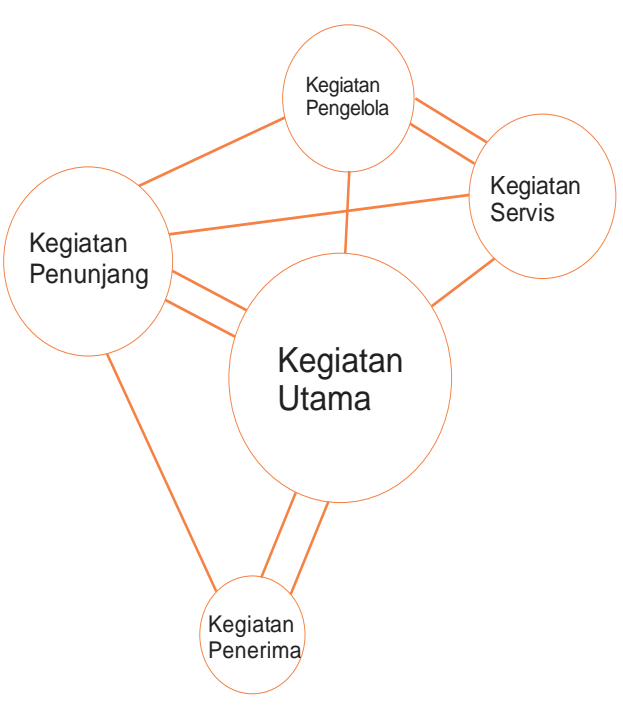

\begin{tabular}{|r|l|}
\hline Nilai & Derajat Keterkaitan \\
\hline$\bigcirc$ & Hubungan erat \\
\hline$\triangle$ & Hubungan kurang erat \\
\hline$\square$ & Tidak ada hubungan ruang \\
\hline
\end{tabular}

Gambar 1. Matrik dan Pola Hubungan Ruang

Pada Gambar 1 terlihat hubungan derajat keterkaitan tiap-tiap kelompok kegiatan. Hubungan keterkaitan ini berfungsi juga pada penataan massa bangunan.

\subsection{Analisis Lokasi}

Selain menentukan lokasi yang strategis, memilih tapak dengan kondisi yang mendukung keberadaan Youth Center ini sangat menentukan prospek bangunan tersebut.

1. Tujuan

Mendapatkan lokasi yang sesuai dengan

Youth Center

2. Dasar Pertimbangan

Posisi tapak strategis untuk ekspose tampilan fisik bangunan dan juga ketercapaian dengan lokasi keramain remaja Kebumen 


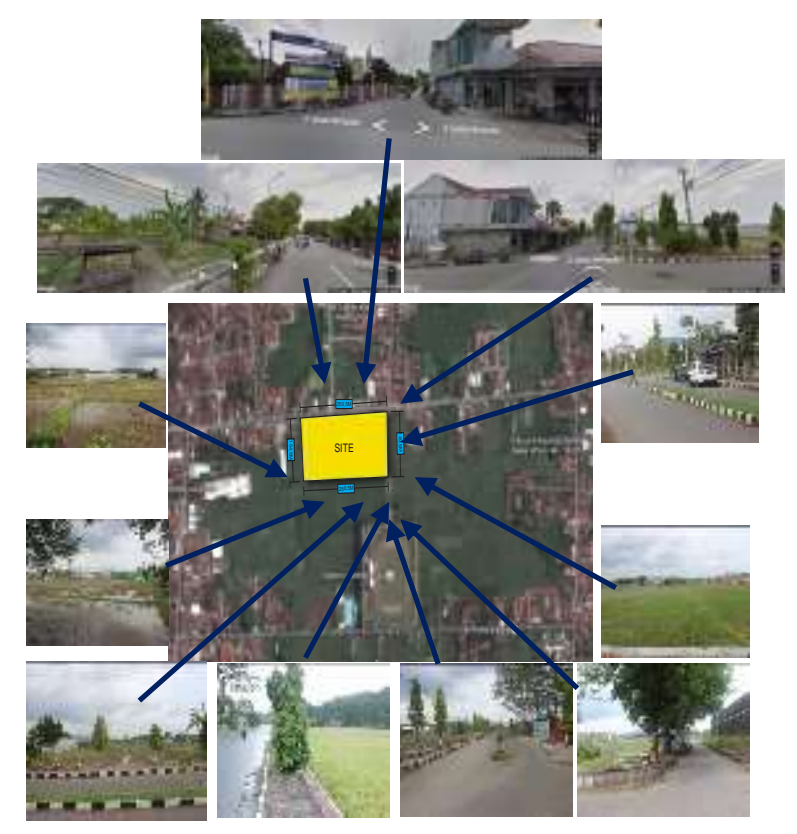

Gambar 2. Analisis Tapak lokasi

Pada Gambar 2 terlihat proses pemilihan lokasi tapak untuk Youth Center di Kebumen dan juga keadaan eksisting tapak.

Tapak terpilih dekat dengan sejumlah sekolah dan tempat keramaian remaja yang digambarkan dengan garis merah tersebut

Data tapak terpilih:

- Lokasi: Jalan Letnan HM Sarbini, Kebumen.

- Luas tapak $: \pm 37.500 \mathrm{~m}^{2}$

- KDB : $50 \%$.

- Lebar jalan : jalan primer $12 \mathrm{~m}$ dan jalan lingkungan $10 \mathrm{~m}$.

\subsection{Analisis Pencapaian}

Pencapaian ke dalam bangunan harus mudah diakses, mudah dilihat dan memiliki sirkulasi yang aman akan menstimulir orang untuk masuk ke dalam area bangunan.

1. Tujuan: menentukan main entrance dan service entrance.

2. Dasar Pertimbangan: kemudahan akses, sirkulasi tapak, arus kendaraan dan potensi jalan, tingkat keamanan

3. Proses analisis

Main Entrance (ME)

Mudah dijangkau dan terlihat dengan jelas. Menghadap langsung ke arah jalan untuk kemudahan sirkulasi kendaraan masuk dan keluar tapak.

Side Entrance (SE)
Tidak mengganggu keberadaan ME. Membantu sirkulasi pengelola dan servis.

\subsection{Analisis Sinar Matahari}

Sinar matahari berfungsi sebagai pencahayaan alami sehingga pemanfaatnya harus maksimal guna menghemat energi buatan dalam hal pencahayaan.

Berikut analisis sinar matahari pada tapak:

1. Massa bangunan untuk kegiatan olahraga ditata agar kena sinar matahari pagi.

2. Pengaturan bangunan bermassa majemuk agar sinar matahari dapat masuk dari selasela bangunan.

3. Memaksimalkan bukaan maupun skylight untuk memasukan cahaya matahari namun ruangan tetap sejuk.

4. Penggunaan vegetasi dan secondary skin sebagai barrier.

\subsection{Analisis Pemintakatan (Penzoningan)}

Pemintakatan berdasarkan sifat kegiatan dan keadaan dalam tapak dilakukan sebagai acuan dalam penataan peruangan, namun tetap memperhatikan kaidah dan prinsip-prinsip Psikologi Arsitektur yang telah diterapkan.

2 Tujuan: Menentukan mintakat (zoning) berdasarkan sifat kegiatan dan keadaan pada tapak.

3 Dasar pertimbangan: analisis peruangan, analisis pengolahan tapak, analisis tema bangunan sesuai Konsep Psikologi Arsitektur.

4 Proses analisis: persyaratan ruang, berdasarkan kelompok kegiatan dan analisis pengolahan tapak.

Tabel 3.Persyaratan Ruang

\begin{tabular}{|l|l|l|l|}
\hline $\begin{array}{l}\text { MINTA } \\
\text { KAT } \\
\text { (ZONING }\end{array}$ & KEL. & \multicolumn{1}{|c|}{ PERSYA } \\
RATAN & $\begin{array}{l}\text { IMPLIKASI } \\
\text { KONSEP } \\
\text { PSIKOLOGI } \\
\text { ARSITEKTUR }\end{array}$ \\
\hline Publik & Penerima & $\begin{array}{l}\text { Pencapaian } \\
\text { mudah } \\
\text { View from/to } \\
\text { site menjadi } \\
\text { pertimbanga } \\
\text { n utama } \\
\text { Pencahayaan } \\
\text { dan } \\
\text { penghawaan } \\
\text { alami } \\
\text { penting }\end{array}$ & $\begin{array}{l}\text { Bangunan harus } \\
\text { menampilkan } \\
\text { kesan terbuka } \\
\text { dan eksploratif } \\
\text { sebagai awal } \\
\text { pengunjung } \\
\text { masuk agar } \\
\text { mendapat } \\
\text { kesanyang } \\
\text { menyenangkan }\end{array}$ \\
\hline & & \\
\hline
\end{tabular}




\begin{tabular}{|c|c|c|c|}
\hline $\begin{array}{l}\text { Semi } \\
\text { publik }\end{array}$ & $\begin{array}{l}\text { Kegiatan } \\
\text { penunjang }\end{array}$ & $\begin{array}{l}\text { Pencapaian } \\
\text { telihat } \\
\text { Noise } \\
\text { penting } \\
\text { Pencahayaan } \\
\text { dan } \\
\text { penghawaan } \\
\text { alami }\end{array}$ & $\begin{array}{l}\text { Aspek } \\
\text { eksploratif dan } \\
\text { dinamis } \\
\text { dikedepankan } \\
\text { dalam penataan } \\
\text { runag maupun } \\
\text { tampilan } \\
\text { bangunan }\end{array}$ \\
\hline privat & $\begin{array}{l}\text { Kegitan } \\
\text { Utama } \\
\text { (Olahraga,k } \\
\text { esenian,kom } \\
\text { unitas,hobi) }\end{array}$ & $\begin{array}{l}\text { Pencapaian } \\
\text { harus } \\
\text { melalui } \\
\text { bangunan } \\
\text { penerima. } \\
\text { Penting } \\
\text { pencahayaan } \\
\text { dan } \\
\text { penghawaan } \\
\text { alami }\end{array}$ & $\begin{array}{l}\text { Tema peruangan } \\
\text { disesuaikan } \\
\text { dengan kegiatan } \\
\text { yang akan } \\
\text { diwadahi, } \\
\text { penekanan } \\
\text { kekuatan, } \\
\text { penekanan } \\
\text { fleksibilitas,ekpl } \\
\text { oratif dan } \\
\text { kejutan adalah } \\
\text { tema-tema yang } \\
\text { nantinya akan } \\
\text { dipakai }\end{array}$ \\
\hline
\end{tabular}

\subsection{Analisis Faktor Bangunan}

Merumuskan suatu konsep perancangan Youth Center sebagai wadah kegiatan remaja yang bisa meningkatkan kreativitas pengguna dalam kegiatan di dalamnya dengan pendekatan Psikologi Arsitektur. "we shape our buildings and afterwards our buildings shape us " (Winston Churchill, 1943 [Laurens, 2004]).

Berikut ini adalah faktor yang menyatakan kondisi lingkungan yang dapat mengembangkan kreativitas (Sari, 2005)

1. Keamanan Psikologis

a. Menerima individu sebagaimana adanya dengan kelebihan dan keterbatasan.

b. Mengusahakan ruang di dalamnya tidak mempunyai efek mengancam.

c. Memberikan pengertian secara empati, penghayatan rasa, dan tindakan individu dari penggunanya

2. Kebebasan psikologis

Lingkungan yang bebas secara psikologis memberikan kesempatan kepada individu untuk bebas mengekspresikan secara simbolis pikiran dan perasaan penggunanya.

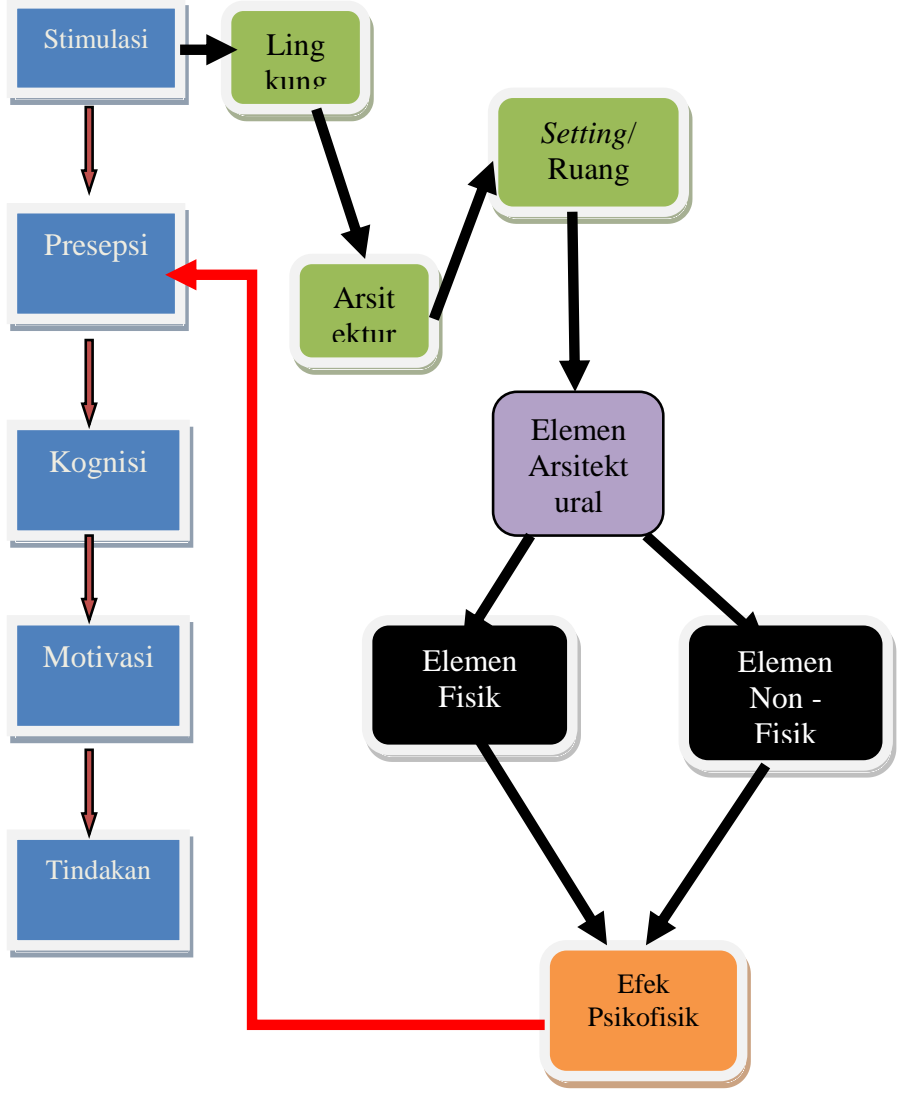

Gambar 3. Skema Efek Psikofisik Terhadap Presepsi dan Tindakan

Pada Gambar 3 terlihat bagaimana elemen arsitektur yang merupakan bagian dari lingkungan bisa direkayasa dengan efek psikofisik sehingga mempengaruhi presepsi dan akhirnya pada sebuah tindakan.

\subsection{Analisis Bentuk dan Gubahan Massa}

Pendekatan bentuk dasar massa bangunan mampu merespon pengguna yaitu remaja agar bisa menimbulkan suasana kenyamanan dan kebebasan psikologis sehingga menimbulkan suasana kreatif.

Tabel 4. Bentuk dan Efek Psikologisnya

\begin{tabular}{|l|l|l|}
\hline BENTUK & $\begin{array}{l}\text { EFEK } \\
\text { PSIKOLOGIS }\end{array}$ & $\begin{array}{l}\text { SIFAT DAN } \\
\text { KARAKTER }\end{array}$ \\
\hline & $\begin{array}{l}\text { Bebas, tidak } \\
\text { terikat, } \\
\text { memungkinkan } \\
\text { keleluasaan } \\
\text { gerak. }\end{array}$ & $\begin{array}{l}\text { Bentuk } \\
\text { segiempat } \\
\text { merupakan } \\
\text { bentuk yang } \\
\text { memiliki sifat } \\
\text { bersudut, statis, } \\
\text { kaku netral, }\end{array}$ \\
\hline
\end{tabular}




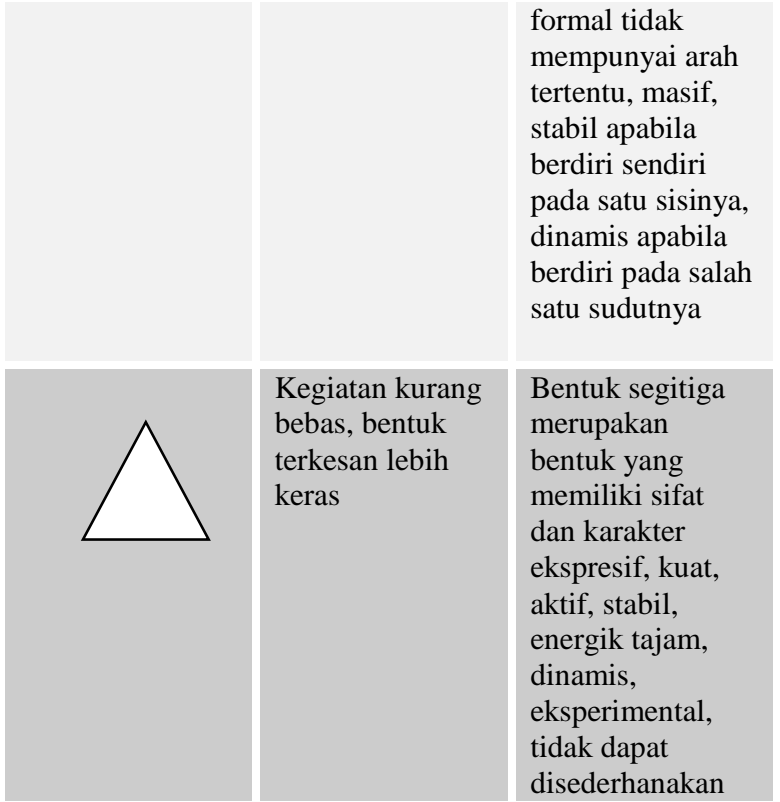

Pada Tabel 4 terlihat bentuk dasar yang dipilih adalah bentuk segitiga dan kotak karena secara psikologis kotak memberi efek gerak yang bebas atau dinamis sedangkan secara karakter segitiga memberi kesan atraktif dan dinamis.

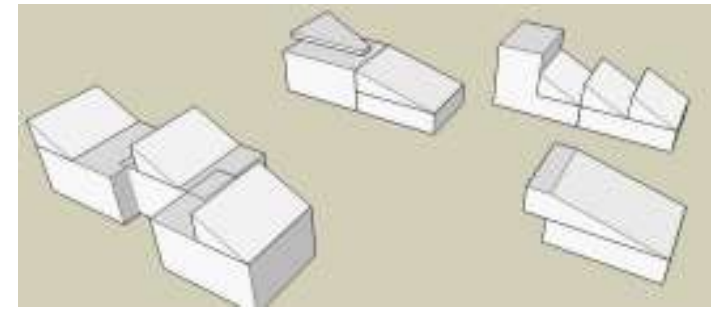

Gambar 4. Gubahan Massa dari Segitiga dan Kotak

\subsection{Analisis Tata Massa Bangunan}

Penataan massa bangunan yang sesuai akan mempengaruhi pengguna bangunan tersebut. Sirkulasi antar bangunan dan pola pencapaian yang terbentuk dari penataan massa bangunan akan memberikan efek tertentu bagi penggunanya. Pada Youth Center di Kebumen ini penataan disesuaikan dengan tema yang diambil yaitu dinamis, ekspresif serta atraktif.

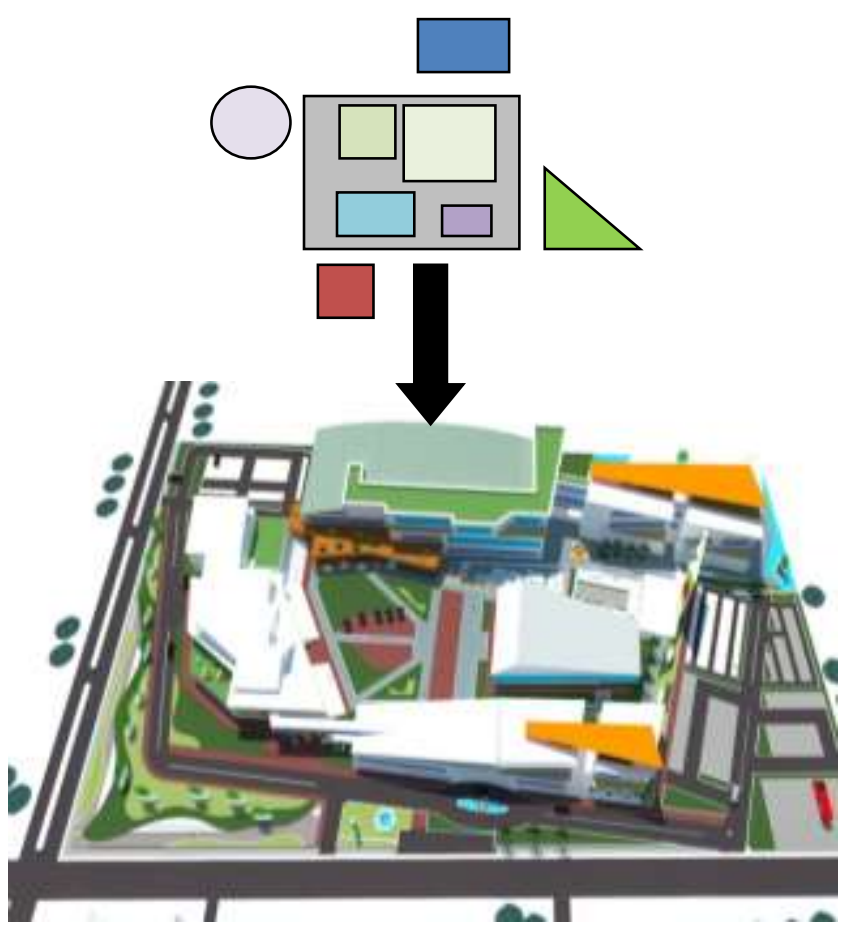

Gambar 5. Pola Cluster pada Penataan Massa Bangunan

Pada Gambar 5 terlihat pola sirkulasi dan pencapaian yang dinamis dan atraktif hal inilah yang akan dirasakan pengguna di dalamnya.

\subsection{Analisis Citra dan Tampilan Bangunan}

Citra dan tampilan bangunan adalah sesuatu yang bisa kita nikmati menggunakan indera penglihatan. Penglihatan terbagi menjadi empat aspek yang bisa direkayasa dalam bidang arsitektur yaitu: bentuk, warna, view dan pencahayaan. Penyelesaian pada rancangan desain Youth Center di Kebumen ini ditonjolkan pada bentuk dan warna material.

Berikut adalah warna dan material yang akan dipakai guna membentuk citra bangunan yang ekspresif, dinamis dan atraktif.

Tabel 5. Warna dan Material serta Efek Psikologis

\begin{tabular}{lll}
\hline Warna & Gambar & $\begin{array}{l}\text { Pengaruh atas } \\
\text { manusia }\end{array}$ \\
\hline Kuning & terang, cerah, lincah, \\
& menggairahkan, \\
& merangsang, \\
& meriangkan secara \\
& mental, meluaskan \\
& kesadaran \\
\hline
\end{tabular}




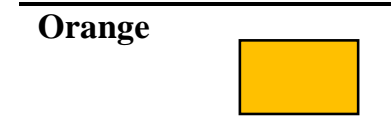

Menanti, mengubah, menggembirakan, menguatkan

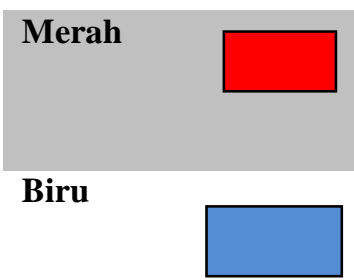

kuat, berapi-api, merangsang, menggiatkan

ketenangan dan penerimaan, dingin, menenangkan, memantapkan,

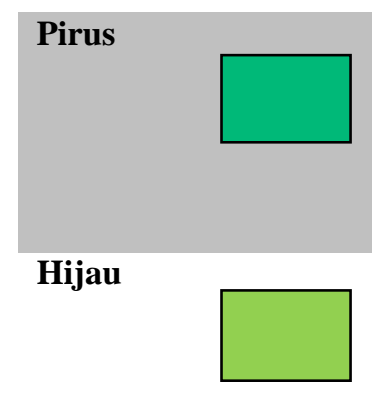

Penyegaran sejuk yang tercipta secara optis, kreatif, komunikatif, teknis, jelas,. emosional.

alamiah, menenangkan, melepaskan, berpengharapan, bersuasana damai, menyelaraskan.

\begin{tabular}{|c|c|c|}
\hline $\begin{array}{l}\text { Kuning } \\
\text { muda }\end{array}$ & \multicolumn{2}{|c|}{$\begin{array}{l}\text { lembut, tentram, } \\
\text { hangat, terang. }\end{array}$} \\
\hline $\begin{array}{l}\text { Hijau } \\
\text { kekuningan }\end{array}$ & \multicolumn{2}{|c|}{$\begin{array}{l}\text { lembut, terlindung, } \\
\text { menggairahkan, } \\
\text { melepaskan. }\end{array}$} \\
\hline BAHAN & GAMBAR & $\begin{array}{l}\text { EFEK } \\
\text { PSIKOLOGIS }\end{array}$ \\
\hline Rumput & & Rileks/santai \\
\hline Tanah & & $\begin{array}{l}\text { Membangkitkan } \\
\text { semangat }\end{array}$ \\
\hline $\begin{array}{l}\text { Batu } \\
\text { kerikil }\end{array}$ & & $\begin{array}{l}\text { Ketenangan, } \\
\text { kesejukan }\end{array}$ \\
\hline $\begin{array}{l}\text { Tanah liat } \\
\text { berpasir }\end{array}$ & & Ketenangan \\
\hline Batu bata & & $\begin{array}{l}\text { Membangkitkan } \\
\text { semangat }\end{array}$ \\
\hline Batu alam & & $\begin{array}{l}\text { Ketenangan, } \\
\text { kesejukan }\end{array}$ \\
\hline
\end{tabular}

Sumber : Frick, 2007:37 dan Frick, 2007:40

Pada Tabel 5 terlihat berbagai macam warna dan material yang akan dipakai beserta efek psikologisnya bagi manusia

\subsection{Analisis Peruangan}

Secara fungional, sistem peruangan yang terbentuk harus dapat memenuhi standarstandar kebutuhan ruang sesuai kegiatan yang diwadahi. Setelah aspek fungsional terpenuhi maka unsur pendekatan Psikologi Arsitektur dimasukan untuk menciptakan setting ruang yang diharapkan. Berikut ini adalah skema setting ruang yang dibutuhkan.

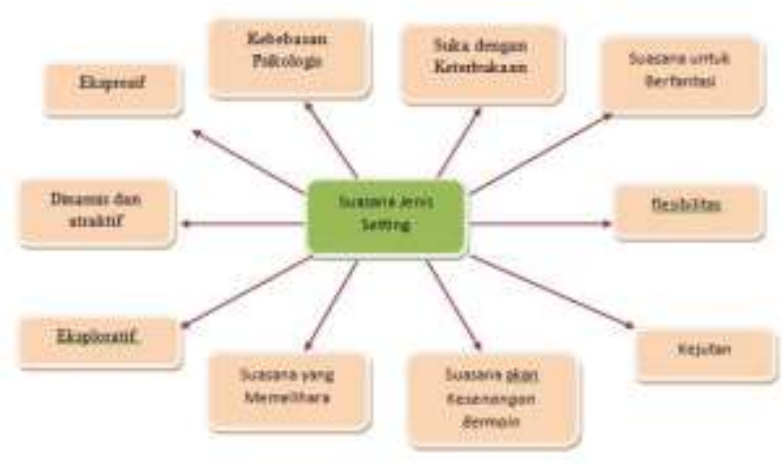

Gambar 6. Skema Tema Setting Peruangan

Pada Gambar 6 terlihat berbagai macam tema setting yang dibutuhkan pada perencanaan ruang Youth Center di Kebumen. Elemen ruang seperti bentuk ruang, warna ruang dan juga jenis material akan direkayasa sehingga membentuk setting tema peruangan yang dibutuhkan sesuai kegiatan yang diwadahi.

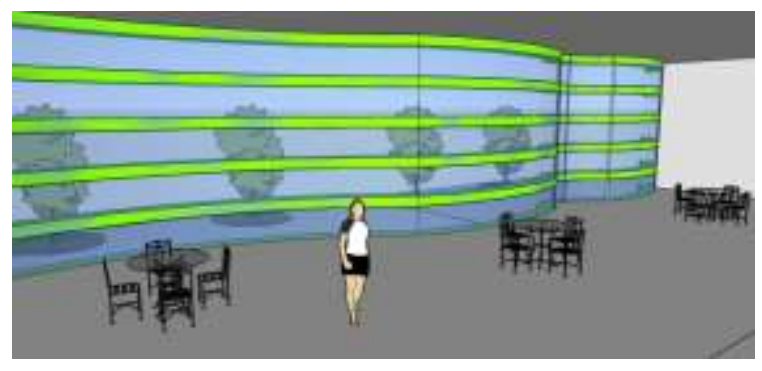

Gambar 7. Contoh Peruangan dengan Kesan Dinamis

Pada Gambar 7 terlihat bagaimana kesan dinamis dalam sebuah ruang terbentuk. Contoh ini baru merekayasa bentuk dan warna dari dari sebuah elemen ruang.

\section{KESIMPULAN (KONSEP DESAIN)}

Konsep rancangan Youth Center di Kebumen mengacu pada pembentukan dan penataan elemen arsitektur untuk menciptakan sebuah wadah remaja agar terpacu kreativitas dalam berkegiatan di dalamnya dengan pendekatan Psikologi Arsitektur. Elemen bentuk, warna dan material menjadi objek yang direkayasa sesuai dengan prinsip-prinsip Psikologi Arsitektur. 
Dari hasil analisa serta hasil kolerasi dari beberapa data di atas, maka diperoleh hasil berupa rancangan Youth Center di Kebumen sebagai berikut.

Nama Bangunan :Youth Center di Kebumen Lokasi : Jalan Letnan HM Sarbini, Kebumen Luas Lahan $\quad: 37.500 \mathrm{~m}^{2}$

Luas Bangunan : $15841 \mathrm{~m}^{2}$

Daya Tampung : 800 orang

Kegiatan : Kegiatan Remaja

Efek Psikofisik merupakan bagian dari Psikologi Arsitektur yang menjadi pokok penerapan dalam pendekatan terhadap objek rancang bangun. Efek penglihatan merupakan hal yang paling ditonjokan untuk mempengaruhi psikologis pengguna yaitu dengan pemilihan bentuk, warna dan material yang sesuai dengan psikologis remaja yang dirangkum dalam tema-tema setting ruang yang telah direncanakan.

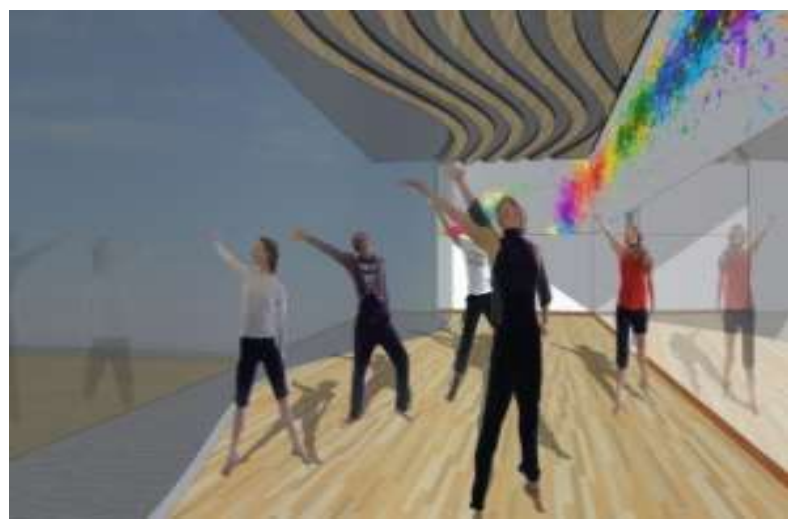

Gambar 8. Interior Ruang Tari

Pada Gambar 8 terlihat bagaimana sebuah ruang tari dengan bentuk yang dinamis berupa lengkungan kaca di sebelah kiri dengan view bebas serta penggunaan warna yang hidup dan juga penerapan materil kayu di plafon dan lantai sebagai unsur ketenangan.

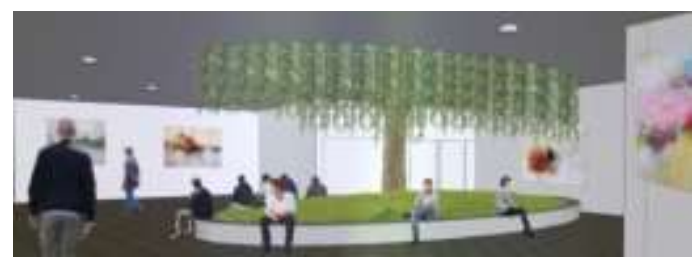

Gambar 9. Interior Ruang Tunggu Kesenian
Pada Gambar 9 terlihat sebuah ruang tunggu yang didesain menarik dengan material rumput dan vegetasi di dalam ruangan guna memberi ketenangan dan membangkitkan inspirasi.

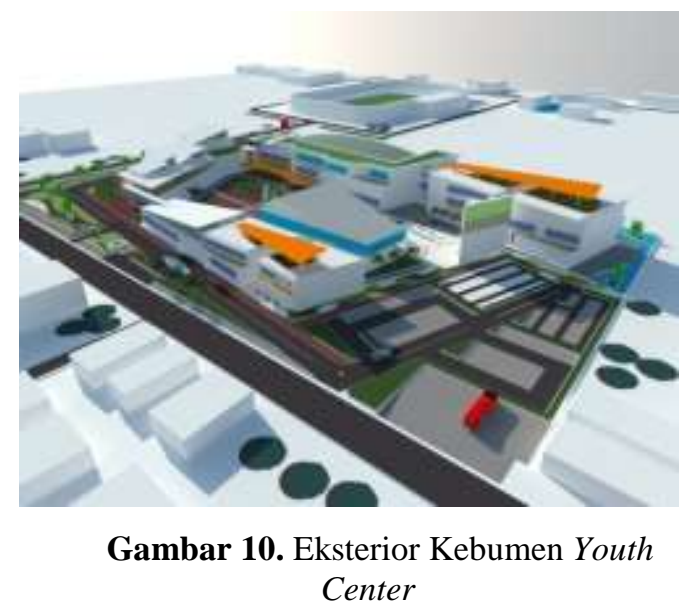

Pada Gambar 10 terlihat penataan massa dan pewarnaan bangunan disesuaikan agar terlihat dinamis dan atraktif.

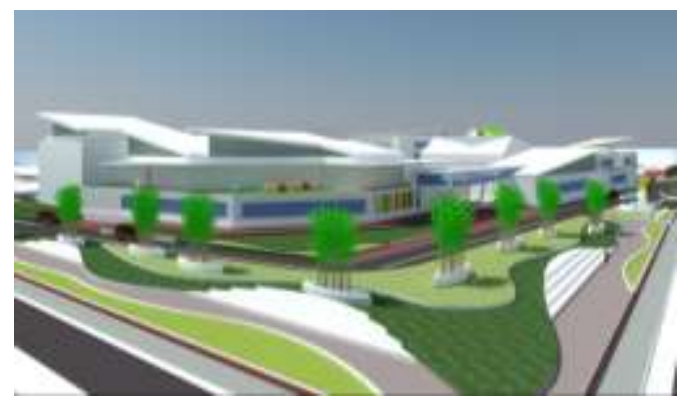

Gambar 11. Ruang Publik Sebagai Penarik Pengunjung dengan Desain yang Dinamis

Pada Gambar 11 terlihat elemen landscape yang dinamis dan didominasi oleh lengkung guna mengimbangi elemen massa bangunan agar dapat menarik perhatian pengunjung. 


\section{REFERENSI}

Badan Pusat Statistik Kabupaten Kebumen tahun 2014 tentang Pendidikan dan Olahraga

Frick, Heinz, 2007, Arsitektur dan Lingkungan. Jakarta: Kanisius

Halim, Deddy, Pd.D, 2005, Buku Psikologi Arsitektur.Jakarta: Penerbit Grasindo.

Laurens, Joyce Marcella, 2004, Arsitektur dan Perilaku Manusia. Jakarta:Grasindo

Sari, Sriti Mayang, 2005. Peran Ruang Dalam Menunjang Perkembangan Kreativitas Anak. Karya Tulis Ilmiah, Jurnal Dimensi Interior Vol.3, No.1. Surabaya: Puslit Univ. Kristen Petra.

www.beritakebumen.info/ www.dikpora.kebumenkab.go.id www.kebumenkab.go.id 